\title{
Genetic Divergence for Yield and Physio-Morphological-Quality Traits in Early Sown Indian Mustard (Brassica juncea (L.) Czern \& Coss.)
}

\author{
Anushree* and Anil Pandey \\ Department of Plant Breeding and Genetics, Dr. Rajendra Prasad Central \\ Agricultural University, Pusa, Samastipur 848125, India \\ *Corresponding author
}

\begin{tabular}{|l|}
\hline K e y w o r d s \\
Indian mustard, \\
physio- \\
morphological \\
traits, early sown, \\
Tocher
\end{tabular}

A B S T R A C T

Climate change has emerged as a biggest environmental challenge for agricultural production worldwide. In this respect, thermo-tolerance is a major objective in many crop sp. including Brassicas. Due to fluctuation in weather parameters, there is needed to develop temperature tolerant Indian mustard varieties for early sown condition. Keeping the facts in view, the present experiment was made to assess the genetic divergence among thirty-five genotypes from different AICRP-RM research centres under early sown condition. Based on $\mathrm{D}^{2}$ analysis, 35 genotypes were grouped into seven clusters. Cluster II had the highest number of nine genotypes followed by cluster I, III, IV, VI accommodated eight, seven, seven and two genotypes respectively. The maximum inter-cluster distance was observed between cluster V and cluster VII exhibiting high degree of genetic diversity which is utilized through hybridization programme. Intra-cluster values varied from 0.00 (mono-genotype) to maximum 281.34 in cluster IV (comprised of the most heterogeneous genotypes) followed by cluster III. Based on highest intercluster distance, mono-genotypic clusters V (DRMR150-35) and VII (TPM-1) followed by VI (KMR10-2 \& Pusa Mahak) and VII (TPM-1) were strikingly divergent, indicating greater diversity.Harvest Index (45.01\%), seeds/siliqua $(22.86 \%)$, days to physiological maturity $(15.80 \%)$ and length of primary mother axis $(14.45 \%)$ showed maximum contribution towards divergence. Based on contribution towards total divergence, inter-cluster distance and cluster mean performance, clusters VII; V and VI genotypes viz. TPM-1; DRMR-150-35 and KMR10-2, Pusa Mahak were most promising divergent genotypes of Indian mustard and subsequently be utilized in intermating i.e.TPM-1/DRMR-150-35; TPM-1/KMR-10-2 \& TPM1/Pusa Mahak for generation of wider variability and could be effectively utilized in hybridization -selection breeding programme to obtain desirable early -sown Indian mustard. 


\section{Introduction}

Genetic diversity plays an important role in plant breeding as it decides the success of any crop improvement programme aiding in the selection of suitable and divergent parents for hybridization. $\mathrm{D}^{2}$ statistic measures degree of diversification and assess relative contribution of different components to the total divergence. In India, Rapeseed-mustard group of crops is one of the major edible oilseed crops cultivated in an area of 5.8 Mha with a production of 6.3Mtonnes.

The average contribution of rapeseed-mustard to the total oilseed was $24.2 \%$ with an average productivity of $1083 \mathrm{~kg} / \mathrm{ha}$ during 2014-2015. (Source: Ministry of Agriculture, Govt. of India).

Indian mustard (B. juncea (L) Czern \& Coss) is one of the most important oil seed crops of the country popularly known as rai, raya or laha predominates contributing about $80 \%$ production of the 6.6 million hectares under rapeseed-mustard in the country.

The crops are very sensitive to climatic variables and hence climate change could have significant effect on its production. High temperature during crop establishment adversely effect on growth and cause considerable yield losses. A part of the decline and stagnation in crop yields causing negative growth rate from 1997 was possibly due to unfavourable monsoon (Arvind Kumar, 2005).

There is a probability of $10-40 \%$ loss in crop production in India with increase in temperature by 2080-2100 (Fisher et al., 2007; Parry et al., 2004; IPCC2007). Therefore, there is a need to develop temperature tolerant Indian mustard varieties for early sown condition to replace toria so that it may offer amphidiploid (AABB) advantage over diploid, elementary species toria (AA) under the agro-ecological situation and which can also fit well in diverse cropping systems.

\section{Materials and Methods}

The material for the present investigation comprised of 35 genotypes obtained from different centres. All genotypes were raised in a Randomized Block Design with three replications during Oct $\left(1^{\text {st }}\right.$ week of October, Mean temperature 34 degree Celsius recorded) 2015 at the research farm of Tirhut College of Agriculture, Dholi, Muzaffarpur. All the recommended agronomic package and protection measures were followed for raising healthy crop.

Each genotype was sown in a plot consisting of three rows of $5 \mathrm{~m}$ length in three replications with inter and intra row spacing of $30 \mathrm{~cm} \times 10 \mathrm{~cm}$. Data were recorded on five randomly selected competitive plants of each genotype in all the replications for twenty one physio-morphological and yield characters viz., Plant height $(\mathrm{cm})(30 \& 60$ DAS $)$, Leaf Area Index (LAI) (at $30 \& 60$ DAS), Specific Leaf Weight (SLW) (at 30 \& 60 DAS), Chlorophyll content (SPAD value) (at $30 \&$ 60 DAS), Crop growth rate (CGR), Days to first flower open (DFFO), Primary branches/plant (PB/PL), secondary branches/plant (SB/PL), siliqua on main shoot (SOMS), seeds per siliqua (SS), length of primary mother axis (LPMA), Seed yield per plant (SY/PL) (g), harvest index (HI) (\%), days to physiological maturity (DPM), dry matter efficiency (DME), 1000 seed weight (1000SW) (g), and oil content(\%).All observations were recorded using standard methodology.

For estimation of leaf area index, specific leaf weight, crop growth rate, the plant samples were uprooted above ground level at 30 and 
60 days after sowing. Each collected sample were separated to different plant parts (root, shoot and leaves) and dried separately at 40$45^{\circ} \mathrm{C}$ in hot air oven for 8-10 days till constant weight was achieved.

The percentage oil content of rapeseed mustard seeds was analysed using a Fosstecator Near Infrared Reflectance Spectroscopy (FT-NIRS). The genetic divergence was estimated by Mahalanobis (1936) $\mathrm{D}^{2}$ statistics and grouping of the genotypes into clusters were done using Tocher method as described by Rao (1952).

\section{Leaf Area Index (30 \& 60 DAS)}

(Watson, 1974) Leaf area index was calculated as the ratio of total leaf area and ground area occupied by the plant.

$$
\mathrm{LAI}=\frac{\text { Total leaf area }(\mathrm{cm} 2)}{\text { Ground area occupied per plant }(\mathrm{cm} 2)}
$$

\section{Specific Leaf Weight (30 \&60 DAS)}

Specific leaf weight was calculated by using the following formula

$\operatorname{SLW}\left(\mathrm{mg} / \mathrm{cm}^{2}\right)=$

$$
\frac{\text { Total leaf dry matter (mg) }}{\text { Total leaf area }(\mathrm{cm} 2)}
$$

\section{Crop Growth Rate (30 \&60 DAS)}

(Buttery, 1979) Crop growth rate was calculated by using the following formula

Where,

$$
\operatorname{CGR}\left(\mathrm{gm}^{-2} \mathrm{day}^{-1}\right)=\frac{\left(\mathbf{w}_{2}-\mathbf{w}_{1}\right)}{\left(\mathrm{t}_{2}-\mathbf{t}_{1}\right)}
$$

$\mathrm{W}_{1} \& \mathrm{~W}_{2}=$ Initial and final dry weight of plant material respectively per unit ground area.

$\mathrm{t}_{1} \& \mathrm{t}_{2}=$ Time of observation in days

\section{Results and Discussion}

In the present investigation thirty-five genotypes under study were found to be grouped in seven clusters (Table 1). Cluster II included maximum number of genotypes (9) followed by cluster I (8) while cluster III, IV and VI accommodated seven, seven and two genotypes respectively. Cluster V and VII were mono-genotypic each having a single genotype, namely, DRMR-150-35 and TPM1 , respectively. indicating distinctness from other genotypes.

The clustering pattern of the experiment is in close agreement with the findings of Alie et al., 2009, Dodabhimappa, 2010 and Kumar and Pandey, 2013.

The spectrum of inter-cluster value $\mathrm{D}^{2}$ in field experiment ranged with a minimum value of 337.241 to maximum value of 2637.099. Oligo-genotypic Cluster V (DRMR-150-35) and VII (TPM-1) were strikingly diverse from the rest of the clusters, as evident from their high inter cluster $\mathrm{D}^{2}$ value (2637.099). Therefore, the genotype falling in these clusters were genetically more divergent. Inter mating the genotype from these two clusters may generate wider variability and is expected to have high yielding transgressive segregants in a population improvement programme.

The minimum inter-cluster $\mathrm{D}^{2}$ value (337.241) was observed between cluster II and III indicating close genetic relationship between genotype of these two clusters. Singh et al., (2010) reported maximum inter-cluster distance between cluster IV and VIII followed by cluster IV and VI and between cluster IV and $\mathrm{V}$.

The lowest inter-cluster distance was found between cluster VII and IX, indicating a close relationship between them. Maximum inter 
cluster distance was found in cluster $\mathrm{V}$ and cluster VI by Bind et al., (2015). The values of intra-cluster distance ranged from 0 (cluster $\mathrm{V}$ and VII) to 281.337 (cluster IV) (Table 2). The intra cluster distance was highest in cluster IV (281.337) followed by cluster III and IV, whereas two mono-genotype clusters (V and VII) had zero intra cluster distance. Similarly, Bind et al., (2015) found maximum intra cluster divergence in cluster III followed by cluster IV and cluster VI. Singh et al., (2010) reported highest intra-cluster distance in cluster II and in cluster IV.

Considering the best cluster mean(Table 3), clusters VI (Pusa Mahak and KMR-10-2) had secured highest cluster mean for maximum characters viz., PH (30 DAS), LAI (30 DAS DAS), CC (60 DAS), SLW (30 \&60 DAS), PB/Pl, SB/Pl and LPMA followed by cluster
V (DRMR-150-35) reflected highest cluster mean for late days to first flower open and DPM as well as seeds/siliqua and seed yield/plant ; cluster VII (TPM-1) showed superiority for early DPM, tall PH (30 DAS), SOMS, HI and DME; cluster III for LAI (60 DAS) and CGR; remaining clusters II and cluster I for CC (30 DAS) and oil content, respectively. This indicated cluster wise promising genotypes for mentioned traits which can be extensively used for mustard breeding programmes to generate new material.

Most important character contributing towards the divergence was harvest index followed by seeds/siliqua, days to physiological maturity and length of primary mother axis (Figure 2).

Table.1 Grouping of thirty-five genotypes into seven clusters based on Tocher's method

\begin{tabular}{|c|c|c|c|}
\hline SI. No & Cluster & $\begin{array}{c}\text { No. of } \\
\text { genotypes }\end{array}$ & Name Of the genotypes \\
\hline 1 & I & 8 & $\begin{array}{l}\text { Kanti, NDRE-7, RH8814, RH-0116, RGN-13, PusaAgrani, RAURDE-1002, RH- } \\
0701\end{array}$ \\
\hline 2 & II & 9 & $\begin{array}{c}\text { Pusa Bahar, RH-30, RH-0406, Pusa Bold, Varuna, RH-0819, PM-25, R. } \\
\text { Sufalam, PM-27 }\end{array}$ \\
\hline 3 & III & 7 & Pant Rai-19, NDRE-4, PKRS-25, RAURD-78, TM-4, NRC-DR-2, PM-28 \\
\hline 4 & IV & 7 & $\begin{array}{l}\text { RAURD-212, RGN-48, RAURDE-1001, KMR-10-1, DRMR-EJ-902, Pusa } \\
\text { Tarak, TM-2 }\end{array}$ \\
\hline 5 & V & 1 & DRMR-150-35 \\
\hline 6 & VI & 2 & KMR-10-2, Pusa Mahak (NC) \\
\hline 7 & VII & 1 & TPM-1 \\
\hline
\end{tabular}

Table.2 Average Intra and Inter Cluster $\mathrm{D}^{2}$ values among the cluster of Indian mustard genotypes

\begin{tabular}{|c|c|c|c|c|c|c|c|}
\hline Cluster & I & II & III & IV & V & VI & VII \\
\hline I & $\mathbf{1 1 6 . 3 1 5}$ & 491.919 & 713.828 & 294.078 & 1453.966 & 1026.457 & 358.603 \\
\hline II & & $\mathbf{1 7 2 . 6 3 3}$ & 337.241 & 497.174 & 482.613 & 471.120 & 1240.765 \\
\hline III & & & $\mathbf{2 3 2 . 0 4 0}$ & 840.525 & 551.948 & 942.350 & 1570.810 \\
\hline IV & & & & $\mathbf{2 8 1 . 3 3 7}$ & 1354.100 & 763.230 & 656.950 \\
\hline V & & & & & $\mathbf{0 . 0 0 0}$ & 608.056 & $\mathbf{2 6 3 7 . 0 9 9}$ \\
\hline VI & & & & & & $\mathbf{2 2 1 . 7 3 3}$ & $\mathbf{1 9 0 1 . 2 4 2}$ \\
\hline VII & & & & & & & $\mathbf{0 . 0 0 0}$ \\
\hline
\end{tabular}


Table.3 Cluster means for twenty-one characters in thirty-five genotypes of Indian mustard

\begin{tabular}{|c|c|c|c|c|c|c|c|c|c|c|c|c|c|}
\hline Cluster & $\begin{array}{c}\text { PH } \\
\text { (30DAS) }\end{array}$ & $\begin{array}{c}\text { PH } \\
\text { (60DAS) }\end{array}$ & $\begin{array}{c}\text { LAI } \\
\text { (60DAS) }\end{array}$ & \multicolumn{2}{|c|}{$\begin{array}{c}\text { LAI } \\
(60 D A S)\end{array}$} & \multicolumn{2}{|c|}{$\begin{array}{c}\text { CC } \\
\text { (30DAS) }\end{array}$} & \multicolumn{2}{|c|}{$\begin{array}{c}\mathrm{CC} \\
(\text { 60DAS) }\end{array}$} & $\begin{array}{c}\text { SLW } \\
(30 D A S)\end{array}$ & $\begin{array}{c}\text { SLW } \\
\text { (60DAS) }\end{array}$ & DFFO & CGR \\
\hline I & 17.896 & 102.805 & 0.501 & \multicolumn{2}{|c|}{3.333} & \multicolumn{2}{|c|}{22.817} & \multicolumn{2}{|c|}{29.333} & 0.007 & 0.012 & 44.208 & 0.503 \\
\hline II & 18.444 & 107.809 & 0.602 & \multicolumn{2}{|c|}{4.772} & \multicolumn{2}{|c|}{24.341} & \multicolumn{2}{|c|}{33.574} & 0.006 & 0.016 & 42.963 & 0.573 \\
\hline III & 18.619 & 103.671 & 0.903 & \multicolumn{2}{|c|}{5.006} & \multicolumn{2}{|c|}{22.643} & \multicolumn{2}{|c|}{28.981} & 0.006 & 0.017 & 46.143 & 0.621 \\
\hline IV & 19.267 & 100.935 & 0.798 & \multicolumn{2}{|c|}{3.955} & \multicolumn{2}{|c|}{22.952} & \multicolumn{2}{|c|}{32.924} & 0.007 & 0.013 & 47.810 & 0.390 \\
\hline V & 18.600 & 96.943 & 0.570 & \multicolumn{2}{|c|}{3.097} & \multicolumn{2}{|c|}{22.600} & \multicolumn{2}{|c|}{38.700} & 0.006 & 0.011 & 50.000 & 0.613 \\
\hline VI & 19.400 & 80.857 & 0.965 & \multicolumn{2}{|c|}{4.250} & \multicolumn{2}{|c|}{20.583} & \multicolumn{2}{|c|}{44.633} & 0.007 & 0.017 & 43.000 & 0.477 \\
\hline VII & 16.067 & 122.343 & 0.460 & \multicolumn{2}{|c|}{2.903} & 22. & 100 & \multicolumn{2}{|c|}{24.000} & 0.005 & 0.007 & 40.000 & 0.560 \\
\hline Cluster & PB/PL & SB/PL & SOMS & SS & $\mathbf{L P}$ & MA & SY/P & & HI & DPM & DME & $\begin{array}{l}1000 \\
\text { SW }\end{array}$ & Oil Content (\%) \\
\hline I & 7.717 & 19.067 & 43.400 & 14.679 & 185 & .725 & 15.23 & & 30.349 & 101.583 & 1.288 & 5.320 & 39.426 \\
\hline II & 7.911 & 19.719 & 45.459 & 13.770 & 203 & .015 & 18.29 & & 24.805 & 112.222 & 1.141 & 5.608 & 38.751 \\
\hline III & 7.800 & 25.343 & 42.638 & 16.581 & 199 & .443 & 18.01 & & 23.481 & 115.619 & 1.101 & 5.425 & 39.168 \\
\hline IV & 7.705 & 18.486 & 45.657 & 13.686 & 192 & .257 & 12.81 & & 23.735 & 103.905 & 1.201 & 5.500 & 39.079 \\
\hline V & 8.000 & 30.600 & 45.667 & 18.067 & 188 & .333 & 26.33 & & 28.556 & 126.333 & 1.077 & 5.680 & 38.190 \\
\hline VI & 9.567 & 46.467 & 44.933 & 15.367 & 219 & .400 & 18.53 & & 23.312 & 114.333 & 1.108 & 5.363 & 39.115 \\
\hline VII & 7.867 & 20.533 & 51.067 & 9.267 & 160 & .133 & 12.53 & & 37.906 & 98.333 & 1.397 & 5.460 & 37.710 \\
\hline
\end{tabular}


Table.4 List of abbreviations:

\begin{tabular}{|l|l|l|}
\hline SI. No. & Traits & Abbreviation \\
\hline $\mathbf{1}$ & Plant Height & PH \\
\hline $\mathbf{2}$ & Leaf Area Index & LAI \\
\hline $\mathbf{3}$ & Chlorophyll Content & CC \\
\hline $\mathbf{4}$ & Specific Leaf Weight & SLW \\
\hline $\mathbf{5}$ & Days to First Flower Open & DFFO \\
\hline $\mathbf{6}$ & Crop Growth Rate & CGR \\
\hline $\mathbf{7}$ & Primary Branches/ Plant & PB/PL \\
\hline $\mathbf{8}$ & Secondary Branches/ Plant & SB/PL \\
\hline $\mathbf{9}$ & Siliqua on Main Shoot & SOMS \\
\hline $\mathbf{1 0}$ & Seeds/ Siliqua & SS \\
\hline $\mathbf{1 1}$ & Length of Primary Mother Axis & LPMA \\
\hline $\mathbf{1 2}$ & Seed Yield/ Plant & SY/PL \\
\hline $\mathbf{1 3}$ & Harvest Index (\%) & HI \\
\hline $\mathbf{1 4}$ & Days to Physiological Maturity & DPM \\
\hline $\mathbf{1 5}$ & Dry Matter Efficiency & DME \\
\hline $\mathbf{1 6}$ & 1000 Seed Weight & 1000 SW \\
\hline $\mathbf{1 7}$ & Days After Sowing & DAS \\
\hline
\end{tabular}

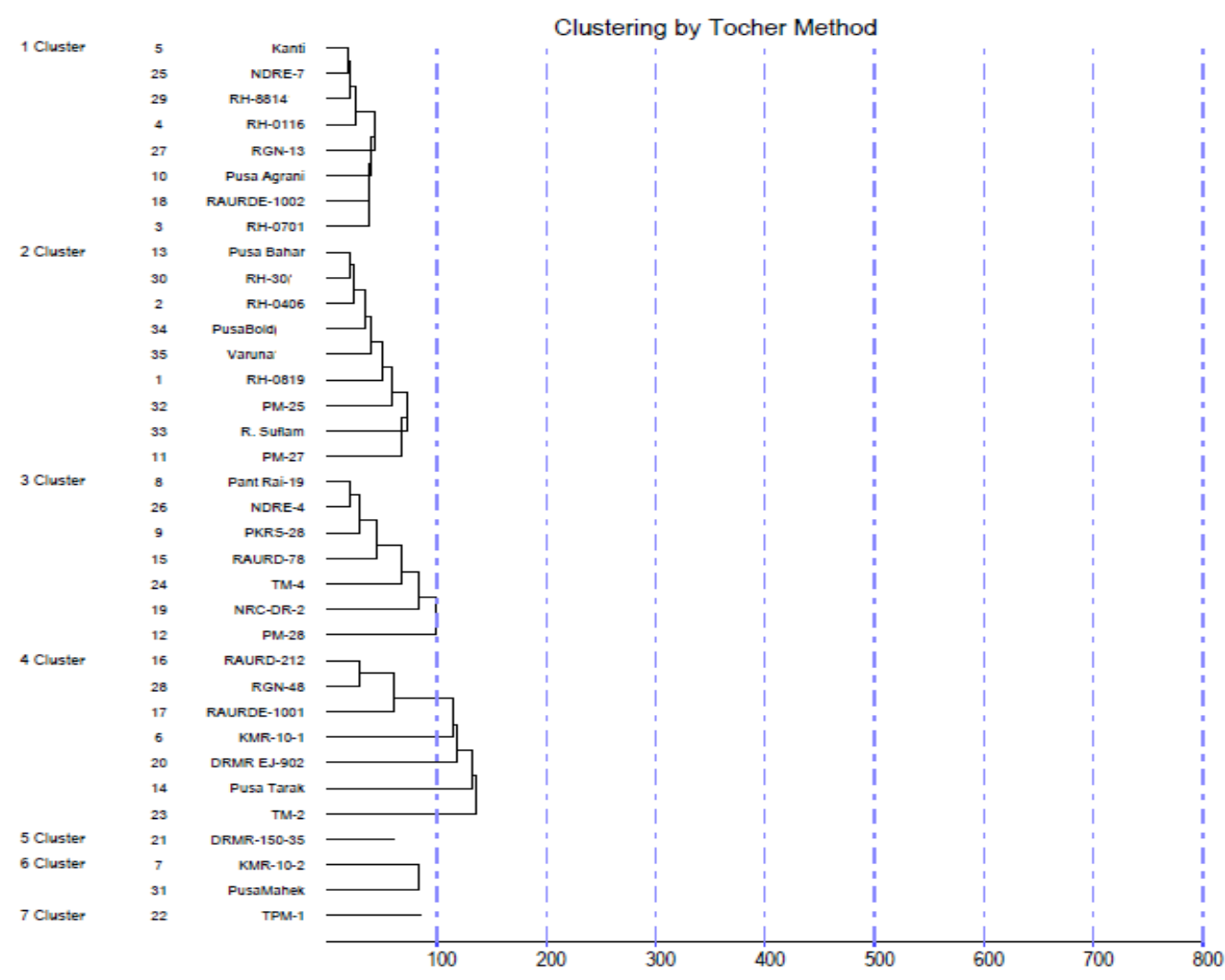

Fig.1 Clustering of 35 Indian mustard genotypes using Tocher's method 


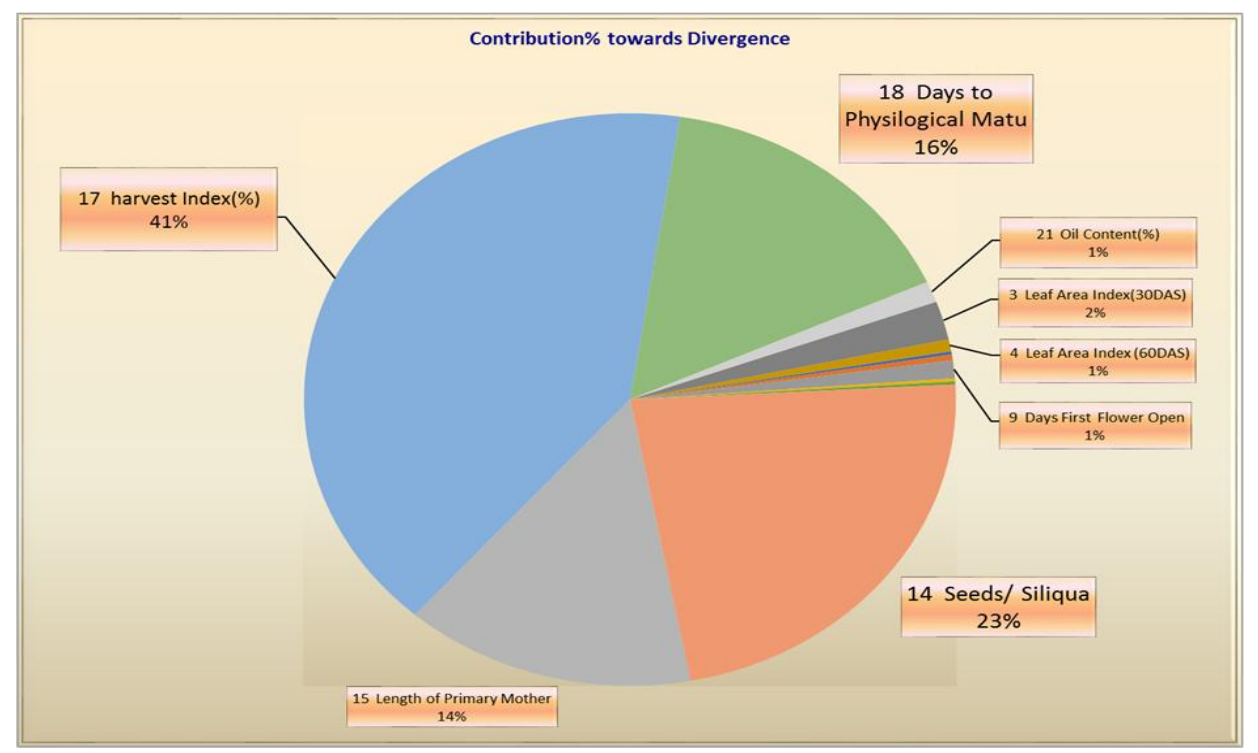

Fig.2 Maximum contribution towards divergence

Clusters V (DRMR150-35) and VII (TPM-1) were mono-genotypic followed by VI (KMR10-2 \& Pusa Mahak) and VII (TPM-1) were strikingly divergent based on highest inter-cluster distance indicating greater diversity, subsequently be utilized in intermating i.e.TPM-1/DRMR-150-35; TPM1/KMR-10-2 \& TPM1/Pusa Mahak for generation of wider variability and utilization in transgressive breeding for development of early -sown mustard. Zaman et al., (2010) observed maximum contribution for days to $50 \%$ flowering followed by days to maturity, plant height, branches per plant and siliquae per plant towards the total divergence in mustard genotypes.

Based on contribution towards total divergence, inter-cluster distance and cluster mean performance, Pusa Mahak, RAURD-78, NRC-DR-2, Varuna, RH-30, PM-25, TPM-1 and NDRE-7 were most promising divergent genotypes of Indian mustard and could be effectively utilized in hybridization-selection breeding programme to develop thermo tolerant Indian mustard under high temperature which would provide superior segregates for physio-morphological-quality yield determinants in Indian mustard genotypes. Some divergent crosses may be suggested for future hybridization-selection breeding programme. These are -
A. Between Cluster V and VII
1.DRMR-150-35/TPM-1
B. Between Cluster VI and VII
1.Pusa Mahak/TPM-1
2.KMR-10-2/TPM-1
C. Between Cluster III and VI
1.RAURD-78/TPM-1
2.NRC-DR-2/TPM-1
D. Between Cluster II \& VII
1. RH-30/TPM-1
2. Varuna/TPM-1
3.PM-25/TPM-1
4. Rajendra Sufalam/TPM-1

E. Between Cluster I \& V

1. RAURD-78/TPM-1

NRC-DR-2/TPM-1

\section{Acknowledgement}

We express thanks to DRMR, Bharatpur, Rajasthan, CCSHAU, Hisar, IARI, New Delhi, GBPUAT, Pantnagar, BARC Trombay, CSAUAT, Kanpur, NDUAT, Faizabad, SKRAU, ARS, Sriganganagar, Rajastahan for providing seed materials for 
the research programme. Thanks to DRMR, Sewar, Bharatpur, Rajasthan for oil estimation of experimental material.

\section{References}

Alie, F.A., Singh T, Tariq and Sharma PK. 2009. Genetic diversity analysis in Indian mustard [Brassica juncea (L.) Czern \& Coss], Progressive Agriculture, 9(1): 50-53.

Anonymous (2014). Agricultural Statistics at a glance (2014), Directorate of Economics and Statistics, Department of Agriculture and Cooperation, Ministry of Agriculture, Government of India

Arvind Kumar, 2005. Rapeseed-mustard in India: current status and future prospects. In: Winter School on Advances in RapeseedMustard Research Technology for Sustainable Production of Oilseeds, National Centre on Rapeseed-Mustard, Sewar, Bharatpur, December 15 to January 04, 2005, pp. 278-288.

Bind, D., Singh, S. and Dwivedi, V. K. 2015. Assessment of genetic diversity and other genetic parameters in Indian mustard [Brassica juncea (L.) Czern and Coss]. Indian.J.Argil. Res., 49: 334-338.

Buttery, (1970). Cited from Book: 11 "Efficiency indices for agriculture management research Authored by P. Devasenapathy, T. Ramesh and B. Ganguar, Pub. New India Publishing Agency (NIPA) -2008s

Doddabhimappa, R., Gangapur B, Prakash G, and Hiremath CP. (2010). Genetic diversity analysis of Indian mustard (Brassica juncea) Electronic Journal of Plant Breeding, 1 (4): 407-413.

Fischer, G., Tubiello, F.N., Velthuizen, H.V., Wiberg, D.A., 2007. Climate change impacts on irrigation water requirements: effects of mitigation, 1990-2080. Technol. Forecasting Soc. Change 74, 1083-1107.
IPCC, 2007. In: Parry, M.L., Canziani, O.F., Paultikof, J.P., van der Linden, P.J., Hanon, C.E. (Eds.), Climate Change - Impacts, Adaptation and Vulnerability Technical Summary of Working Group II to Fourth Assessment Report of Intergovernmental Panelon Climate Change. Cambridge University Press, Cambridge, UK, pp. 2378.

Kumar, B and Pandey A. (2013). Diversity analysis in Indian mustard (Brassica juncea L. Czern \& Coss); Madras Agriculture Journal, 100 (1-3): 62-66.

Mahalanobis, P. C. 1936. On generalized distance in statistics. Proceedings of National Academy of science, India. 2: 49-55.

Parry, M.L., Rosenzweig, C., Iglesias, Livermore, A.M., Fischer, G., 2004. Effects of climate change on global food production under SRES emission and socioeconomic scenarios. Global Environ. Change 14, 5367.

Rao, C. R. 1952. Advanced statistical method in biometrical research. Ed. John Wiley and sons Inc., New York.Edn.1.

Singh, D., Arya RK, Chandra N, Niwas R and Salisbary P. (2010). Genetic diversity studies in relation to seed yield and its component traits in Indian mustard $[B$. juncea (L.) Czern and Coss.], Journal of Oilseed Brassica, 1 (1): 19-22.

Watson, 1947. Cited from Book: 11 "Efficiency indices for agriculture management research Authored by P. Devasenapathy, T. Ramesh and B. Gangwar, Pub. New India Publishing Agency (NIPA) -2008

Zaman, M. A., Khatun, M. T., Ullah, M. Z., Moniruzzamn, M. and Rahman, M. Z. 2010. Multivariate analysis of Divergence in advanced lines of mustard (Brassica spp). Bangladesh J. Pl. Breed. Genet.23(2): 29-34.

\section{How to cite this article:}

Anushree and Anil Pandey. 2020. Genetic Divergence for Yield and Physio-MorphologicalQuality Traits in Early Sown Indian Mustard (Brassica Juncea (L.) Czern \& Coss.). Int.J.Curr.Microbiol.App.Sci. 9(03): 1393-1400. doi: https://doi.org/10.20546/ijcmas.2020.903.162 